\title{
COMPARTIMENTACÃO ESTRUTURAL E CONECTIVIDADE DOS SISTEMAS AQÜÍFEROS CAIUÁ E SERRA GERAL NO NOROESTE DO PARANÁ - BRASIL
}

\author{
Daniel Fabian Bettú ${ }^{1}$, Francisco José Fonseca Ferreira² ${ }^{2}$ Eduardo Salamuni ${ }^{3}$ e Luiz Alberto Fernandes ${ }^{4}$ \\ Recebido em 19 abril, 2006 / Aceito em 27 setembro, 2006 \\ Received on April 19, 2006 / Accepted on September 27, 2006
}

\begin{abstract}
The aeolian sandstones of Caiuá Group (Bauru Basin - Upper Cretaceous - Paraná, northwest of Brazil) are lying on basalts of Serra Geral Formation (São Bento Group - Mesozoic of Paraná Basin) and both form significant aquifers. Although permo-porosity of sandstone is granular, unlike basalts that is crystalline, upper slice of Serra Geral Aquifer System - SGAS - is classified as free, close as Caiuá Aquifer System - CAS. Magnetic susceptibility contrast between rocks allows applying aeromagnetic data to model most prominent structures that form the basement of sandstones. Analysis of sandstones surface was based in morphological/structural interpretation from drainage net, digital elevation model (DEM) and Landsat 7/ETM ${ }^{+}$image. Comparison between two levels of investigation reveal coexistence of some mapped structures and results in a common structural framework. Maps of water discharge, specific capacity, total dissolved solids and cation of water pumped from CAS wells indicate zones with characteristic water from SGAS into CAS, indicate hydraulic connection of refer aquifer systems. Superimpose of hydrogeological maps by common structural framework indicate that presence of larger mapped structures often act on hydrogeological compartments.
\end{abstract}

Keywords: Caiuá Group (Bauru Basin), Serra Geral Formation (Paraná Basin), magnetic method, hydrogeology, structural geology.

RESUMO. No noroeste do estado do Paraná os arenitos eólicos do Grupo Caiuá (Bacia Bauru - Cretáceo Superior) estão dispostos sobre basaltos da Formação Serra Geral (Grupo São Bento - Cretáceo Inferior da Bacia do Paraná). Ambos constituem importantes sistemas aqǘferos. Apesar da permo-porosidade dos basaltos ser do tipo fissural, diferente dos arenitos onde é granular, a porção superior do Sistema Aqǘfero Serra Geral (SASG) apresenta-se livre, em conjunto com o Sistema Aqǘfero Caiuá (SAC). 0 contraste de susceptibilidade magnética entre os basaltos e os arenitos possibilitou o emprego de dados aeromagnéticos para delinear as estruturas mais proeminentes do embasamento dos arenitos. A análise de superfície dos arenitos consistiu na interpretação morfoestrutural a partir da rede de drenagem, modelo digital de elevação (MDE) e imagens Landsat 7/ETM+ ${ }^{+}$. A comparação entre os dois níveis de investigação revelou a coincidência de algumas estruturas mapeadas, resultando em um arcabouço estrutural comum ao SAC e ao SASG. Mapas de sólidos totais dissolvidos (STD) e do conteúdo catiônico das águas de poços produtores completados no SAC, indicaram zonas com características hidroquímicas do SASG em seu interior, denotando a conectividade hidráulica dos dois sistemas aqüiferos. A superposição do arcabouço estrutural integrado aos mapas hidrogeológicos (vazão, capacidade específica e hidroquímicos), revelou que grandes estruturas, freqüentemente, exercem influência na compartimentação hidrogeológica da região.

Palavras-chave: Grupo Caiuá (Bacia Bauru), Formação Serra Geral (Bacia do Paraná), método magnético, hidrogeologia, geologia estrutural.

\footnotetext{
${ }^{1}$ Curso de Pós-Graduação em Geologia Exploratória, Departamento de Geologia, Universidade Federal do Paraná, Rua Camões, 1339, 80040-180 Curitiba, Paraná, Brasil. E-mail: daniel_bettu@yahoo.com.br

${ }^{2}$ Laboratório de Pesquisas em Geofísica Aplicada - LPGA, Curso de Pós-Graduação em Geologia, Departamento de Geologia, Universidade Federal do Paraná, Centro Politécnico, Jardim das Américas, Cx. Postal 19045, 81531-980 Curitiba, Paraná, Brasil. E-mail: francisco.ferreira@ufpr.br

${ }^{3}$ Curso de Pós-Graduação em Geologia, Departamento de Geologia, Universidade Federal do Paraná, Centro Politécnico, Jardim das Américas, Cx. Postal 19045, 81531-980 Curitiba, Paraná, Brasil. E-mail: salamuni@ufpr.br

${ }^{4}$ Curso de Pós-Graduação em Geologia, Departamento de Geologia, Universidade Federal do Paraná, Centro Politécnico, Jardim das Américas, Cx. Postal 19001, 81531-980 Curitiba, Paraná, Brasil. E-mail: lufernandes@ufpr.br
} 


\section{INTRODUÇÃ̃O}

A Bacia Bauru (Cretáceo Superior) atualmente corresponde à região oriental do estado de Mato Grosso do Sul, sul de Goiás, parte do Triângulo Mineiro, planalto ocidental de São Paulo, noroeste do estado do Paraná e parte do Paraguai, abrangendo uma área aproximada de $370.000 \mathrm{~km}^{2}$, na porção centro-sul da Plataforma Sul-Americana. 0 preenchimento sedimentar é caracterizado por uma seqüência siliciclástica continental psamítica, com intercalações localizadas de rochas vulcânicas, sobreposta aos basaltos da Formação Serra Geral (Bacia do Paraná), da qual é separada por uma discordância erosiva (Fernandes \& Coimbra, 1996). No norte e noroeste do estado do Paraná afloram sobretudo arenitos do Grupo Caiuá (Fig. 1), onde localiza-se a área de estudo.

A região estudada está inserida em um contexto tectonoestrutural complexo, com inúmeras zonas de falha, compondo sistemas das mais variadas direções, predominantemente NWSE, NE-SW, E-W e N-S (Ferreira, 1982a,b; Zalán et al., 1987; Soares, 1991). Fernandes (1992) menciona uma "herança tectônica" como responsável pela manutenção dos padrões estruturais do embasamento da Bacia Bauru nas tendências de fraturas da cobertura suprabasáltica, evidenciando nítidas reativações de sistemas pré-Bacia Bauru, durante e após a sedimentação Neocretácea.

Os eventos deformacionais que afetaram a Bacia Bauru e 0 seu embasamento permitiram a geração de zonas de mistura das águas dos sistemas Serra Geral (SASG) e Caiuá (SAC). Como as águas características do SAC são mais diluídas que as do SASG (Rosa Filho et al., 1987), espera-se que as águas do SAC apresentem alterações em suas características químicas nas zonas de conectividade.

Ambas as unidades, Formação Serra Geral e Grupo Caiuá, configuram importantes aqüíferos no estado do Paraná. Na região de afloramentos dos arenitos cerca de $80 \%$ do abastecimento público é feito por água subterrânea. Até a presente data cerca de 840 poços encontram-se cadastrados no banco de dados hidrogeológicos da Suderhsa (Superintendência de Desenvolvimento de Recursos Hídricos e Saneamento Ambiental). 0 Sistema Aqüífero Caiuá (SAC) foi classificado por Rosa Filho (1982) como granular, do tipo livre a semiconfinado. Os poços possuem profundidade média de 110 metros e vazão média de $18 \mathrm{~m}^{3} /$ hora. 0 Sistema Aqüífero Serra Geral (SASG), posicionado na base do SAC, foi classificado como do tipo fissural (fraturado), e, pelo menos em sua porção superior, considerado como aqüífero livre em conjunto com o SAC (Celligoi, 2000). Nos basaltos a circulação e 0 armazenamento de água subterrânea são determi- nados por fraturas e falhas, bem como pelas descontinuidades entre os derrames, em zonas vesículo-amigdaloidais. No estado do Paraná existem cerca de 3.050 poços completados no SASG, os quais possuem profundidade média de 125 metros e vazão média de $14 \mathrm{~m}^{3} /$ hora.

Comumente os parâmetros físico-químicos das águas variam no interior do SAC, principalmente os teores de sólidos totais dissolvidos (STD) e de cátions, com algumas porções indicando características de misturas com águas do SASG (Celligoi, 2000).

\section{MATERIAIS E MÉTODOS}

A determinação do arcabouço estrutural da Bacia Bauru e do seu embasamento foi baseada em dois níveis de investigação. Para a geração do modelo da superfície dos arenitos foram usados os alinhamentos estruturais interpretados com base em imagens Landsat 7/ETM+, modelo digital de elevação (células de $90 \mathrm{~m}$, proveniente do sensor SRTM - Shuttle Radar Topography Mission - NASA) e análise morfoestrutural da rede de drenagem. 0 mapa estrutural do embasamento da bacia foi fundamentado no processamento e na interpretação dos dados aeromagnéticos provenientes do Projeto Aerogeofísico Rio Ivaí (Petrobras, 1980). Por comparação, em ambiente de Sistema de Informação Geográfica (SIG), os modelos estrutural e morfoestrutural foram harmonizados em um arcabouço estrutural integrado.

Por meio do confronto dos mapas hidrogeológicos/hidroquímicos e do arcabouço estrutural integrado, da bacia e do seu embasamento, o presente trabalho discute a influência estrutural no condicionamento das zonas de mesclagem de águas, assim como a compartimentação dos dois sistemas aqüíferos.

Foram avaliados os teores de STD, as vazões e as capacidades específicas de 222 poços de exploração completados no Grupo Caiuá, cujos dados foram cedidos pela Companhia de Saneamento do Paraná (Sanepar, 2002) e pela Superintendência de Desenvolvimento de Recursos Hídricos e Saneamento Ambiental (Suderhsa, 2002). Com base nas análises químicas de 46 amostras, cujo erro de balanço iônico foi inferior a 10\% (Celligoi, 2000), foi possível avaliar e interpretar a distribuição espacial dos teores de cátions do SAC.

\section{CARACTERIZAÇÃO GEOLÓGICA}

Na região afloram arenitos eólicos do Grupo Caiuá, assentados sobre os basaltos da Formação Serra Geral (Grupo São Bento, Bacia do Paraná), limitados por uma discordância erosiva (Fernandes \& Coimbra, 1996). 0 mapa geológico simplificado da região é mostrado na Figura 1. 


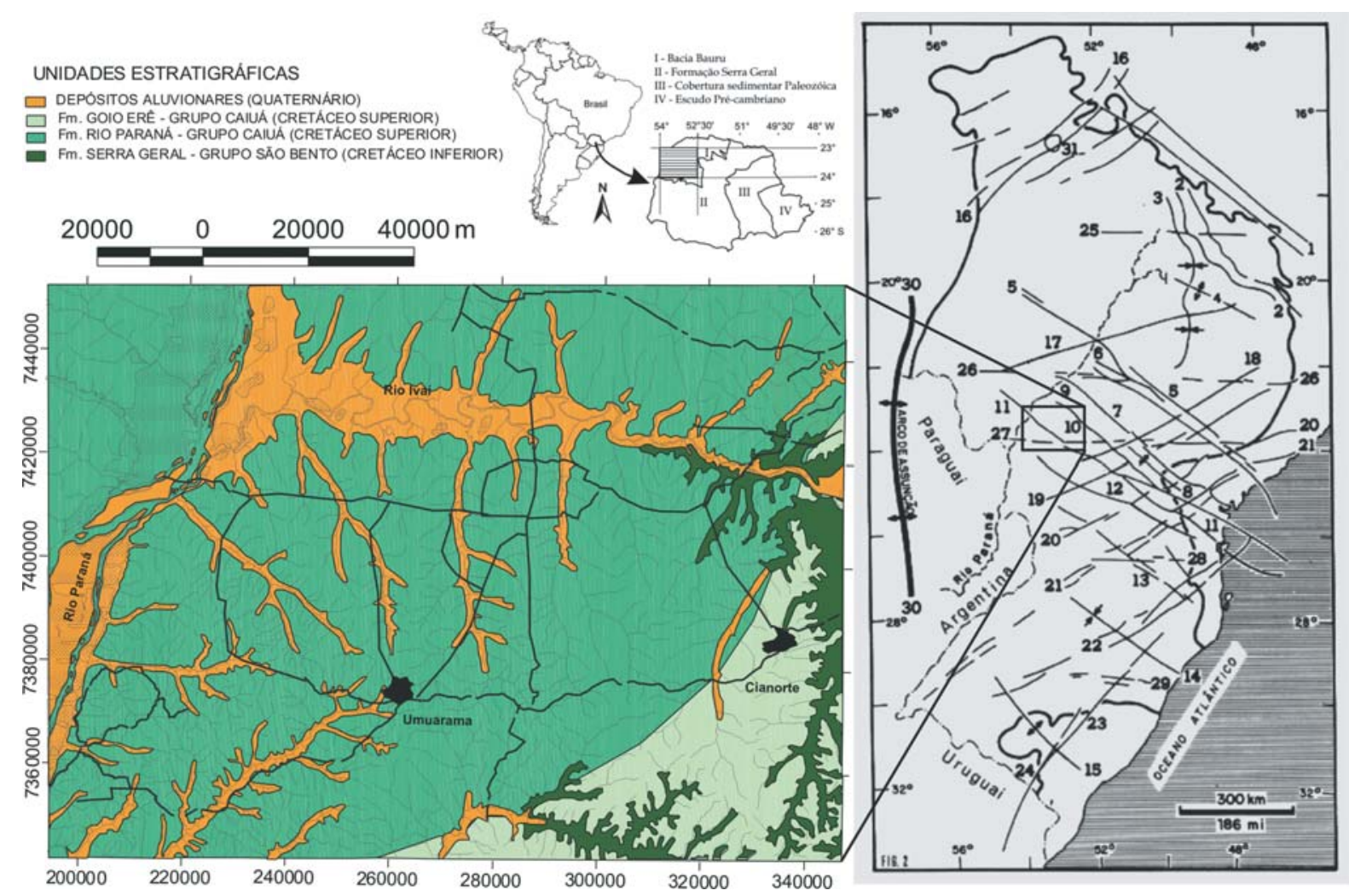

Figura 1 - Localização da área, mapa geológico (CPRM, 2001) e mapa do arcabouço estrutural da Bacia do Paraná (modificado de Zalán et al., 1987).

Para Fernandes \& Coimbra ( $O p$. cit) o vulcanismo gerador da Formação Serra Geral marcou o final da sedimentação na Bacia do Paraná, durante o Cretáceo Inferior, resultando em subsidência mecânica causada pelo peso das rochas basálticas. Foi gerada então uma depressão no centro-sul da Plataforma Sul-Americana, posteriormente preenchida no Cretáceo Superior pelos sedimentos provenientes das bordas alçadas.

$\mathrm{Na}$ área de estudo a Bacia Bauru compreende as formações Goio-Erê e Rio Paraná, do Grupo Caiuá, lateralmente interdigitadas (Fig. 2) e correspondendo, respectivamente, à periferia e ao centro do sand sea do ambiente desértico ao qual é atribuída sua deposição (Fernandes \& Coimbra, 1996). A espessura da Formação Rio Paraná em toda a bacia não ultrapassa $277 \mathrm{~m}$, enquanto a Formação Goio-Erê alcança no máximo 50 m (Fernandes, 1992). As rochas variam de arenitos finos a muito finos, quartzosos, embora a presença de microclínio seja comum, em porcentagens muito pequenas. Os arenitos são bem selecionados, conferindo às rochas alta porosidade primária, que pode diminuir localmente por conta de variações granulométricas e de cimentação. Esta última é mais expressiva na porção basal dos arenitos, onde ocorre cimentação carbonática.

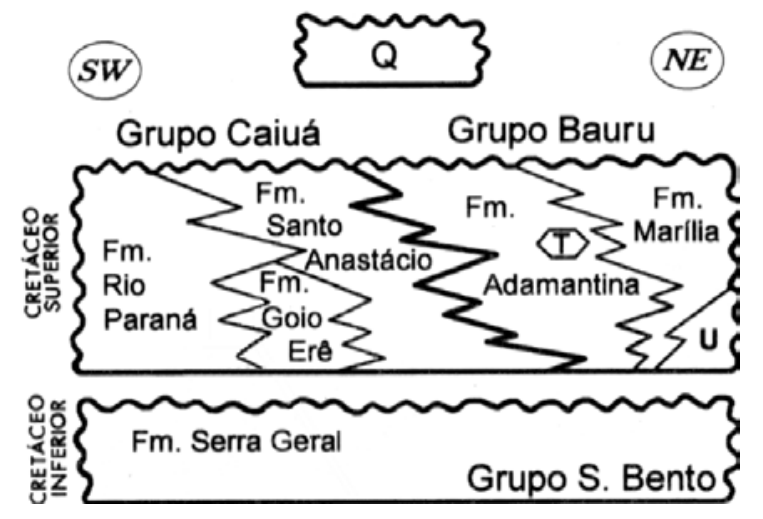

Figura 2 - Coluna litoestratigráfica da Bacia Bauru. Convenções U. Fm Uberaba; T. Analcimitos Taiúva; Q. Sedimentos aluviais quaternários (Fernandes, 1992).

A evolução tectônica da região resultou na ocorrência de grandes alinhamentos estruturais, muitos deles afetando os arenitos do Grupo Caiuá (Ferreira, 1982 a,b; Almeida, 1986; Zalán et al., 1987; Soares, 1991).

Zalán et al. (1987) apresentaram um mapa do arcabouço Bacia do Paraná (Fig. 1), indicando as estruturas mais importantes que afetaram a área de estudo: 10 - Falha do Rio Alonzo (NW-SE), 
11 - Zona de Falha Cândido de Abreu-Campo Mourão (NW-SE) e 27 - Lineamento de São Sebastião (EW). Soares (1991) identificaram cinco direções predominantes na estruturação da Bacia do Paraná: Paraná (N25E), Pitanga (N60E), Rio Ivaí (N45W), Rio Piquiri (N70W), Goioxim (N5-20W).

\section{ANÁLISE GEOFÍSICA DE SUBSUPERFÍCIE}

A análise estrutural do embasamento do Grupo Caiuá na área de estudo foi apoiada no processamento de dados aeromagnetométricos (Petrobras, 1980), os quais foram adquiridos a uma altura média de $450 \mathrm{~m}$, intervalo de amostragem de $56 \mathrm{~m}$, segundo linhas de produção dispostas na direção NS, espaçadas de $2.000 \mathrm{~m}$, e linhas de controle perpendiculares separadas de $20.000 \mathrm{~m}$ (Fig. 3).

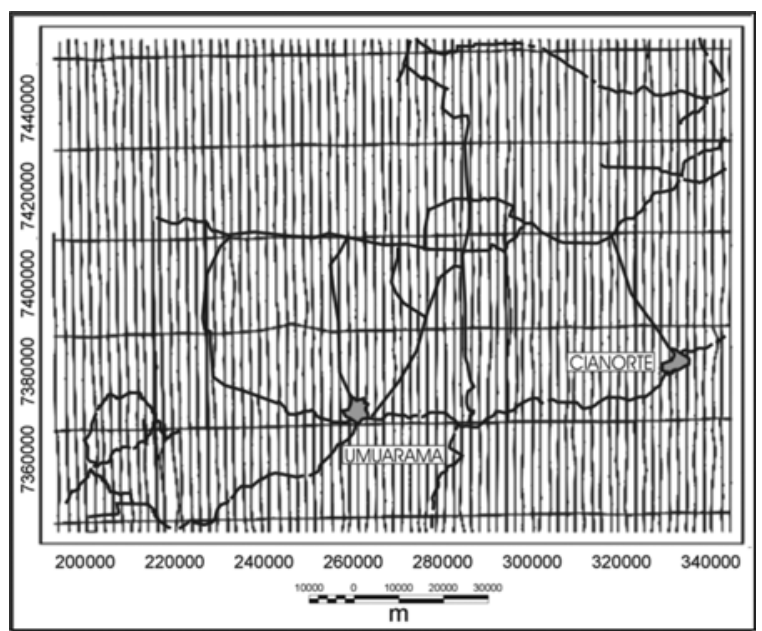

Figura 3 - Mapa de linhas de produção e de controle da área de estudo.

Os dados magnéticos, subtraídos do campo principal da Terra (/GRF - International Geomagnetic Reference Field), foram interpolados na forma de uma malha regular, com células de $500 \mathrm{~m}$ (1/4 do espaçamento das linhas de vôo), através do método da curvatura mínima (Briggs, 1974). Os dados residuais foram micronivelados pelo método da decorrugação FFT (Transformada Rápida de Fourier) para a minimização dos erros de nível do levantamento, baseado no algoritmo proposto por Minty (1991). 0 mapa magnético residual micronivelado é mostrado na Figura 4.

\section{Continuações para cima}

0 filtro de continuação para cima simula o campo magnético para alturas superiores aquela do levantamento geofísico. Os dados magnéticos, adquiridos a uma altura de $450 \mathrm{~m}$, foram simulados para as alturas de 1.000 e $4.000 \mathrm{~m}$. A Figura 5 mostra o mapa do campo magnético continuado para 1.000. Este procedimento causou a eliminação dos sinais de alta frequêencia espacial (ruídos e estruturas menores), preservando as anomalias de grandes comprimentos de onda, reflexo de fontes profundas.

\section{Deconvolução de Euler}

0 método de Deconvolução de Euler foi aplicado com o objetivo de definir a distribuição espacial das fontes magnéticas e determinar as estatísticas de suas profundidades. Esta técnica tem como vantagens não necessitar o conhecimento da direção do vetor de magnetização, nem a determinação de seu módulo. 0 método é baseado na equação de homogeneidade de Euler, a qual relaciona o campo magnético e suas derivadas horizontais e vertical com a localização da fonte, utilizando o índice estrutural $\mathbf{N}$ (Thompson, 1982). 0 índice estrutural é a medida da taxa de mudança da intensidade do campo potencial frente à distância entre a fonte e 0 detector, para uma determinada geometria do modelo.

A Deconvolução de Euler foi aplicada nas malhas continuadas para cima (1.000 e $4.000 \mathrm{~m}$ ), utilizando os índices estruturais referentes a contato geológico $(0)$ e degrau magnético $(0,5)$.

A Figura 6 mostra as soluções calculadas para 0 campo magnético continuado a $1.000 \mathrm{~m}$, onde a maioria das fontes está situada entre 250 e $2.500 \mathrm{~m}$ de profundidade, com classe modal entre 750 e 1.000 m (Bettú, 2004).

\section{Sinal analítico}

A função amplitude do sinal analítico de ordem zero (simples), baseada nas derivadas horizontais e vertical, é representada pela equação abaixo:

$$
|A(x, y, z)|=\left[\left(\frac{\partial M}{\partial x}\right)^{2}+\left(\frac{\partial M}{\partial y}\right)^{2}+\left(\frac{\partial M}{\partial z}\right)^{2}\right]^{1 / 2}
$$

onde $\left(\frac{\partial M}{\partial x}\right)$ e $\left(\frac{\partial M}{\partial y}\right)$ representam as primeiras derivadas horizontais do campo magnético, respectivamente nas direções $x$ e $y$ e $\left(\frac{\partial M}{\partial z}\right)$ é a primeira derivada vertical (Nabighian, 1972).

A função amplitude do sinal analítico tem forma de sino (bell shaped), com amplitude máxima situada exatamente sobre o topo da fonte, e suas dimensões se relacionam diretamente com a profundidade do corpo, em qualquer ordem de derivação (Nabighian, 1974), o que explica sua ampla utilização no mapeamento magnético.

Foram calculadas as amplitudes do sinal analítico com base nas malhas dos campos magnéticos continuados para $1.000 \mathrm{e}$ $4.000 \mathrm{~m}$. A Figura 7 mostra 0 mapa da amplitude do sinal analítico de ordem zero do campo magnético continuado para 


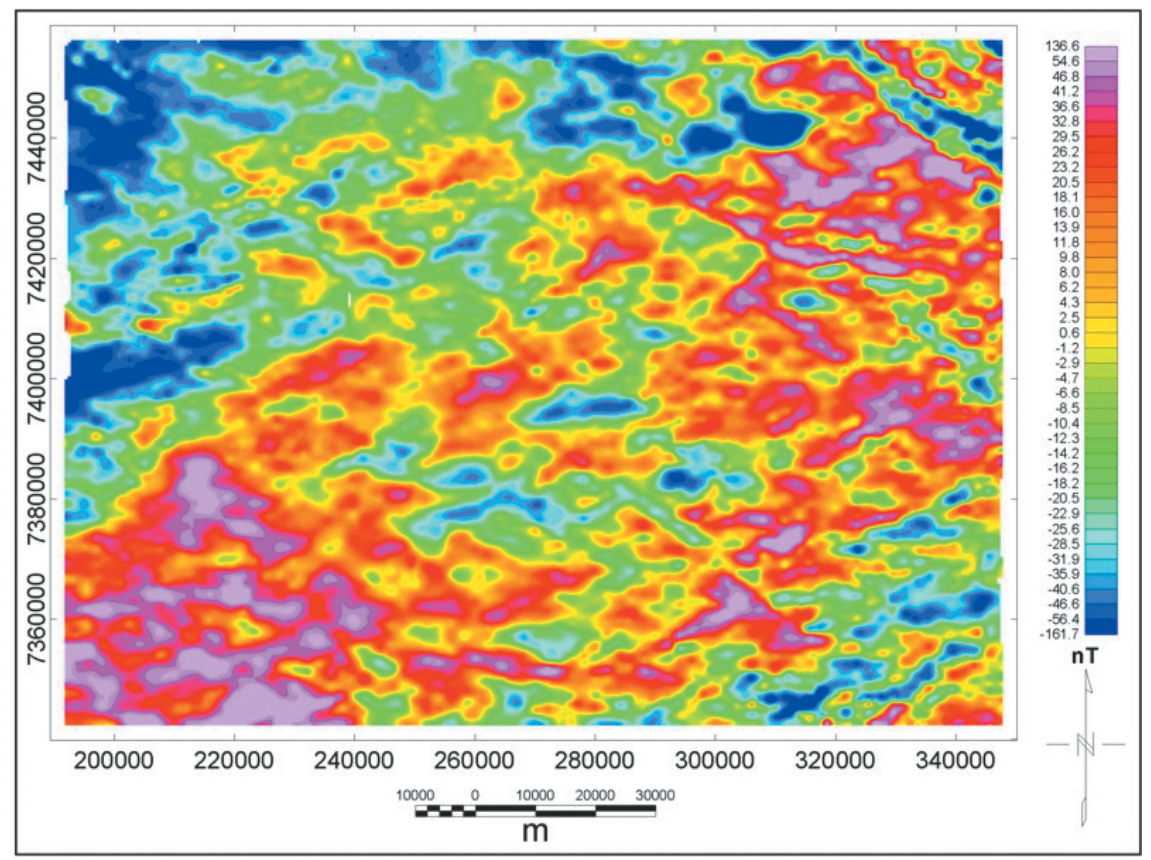

Figura 4 - Mapa magnético residual micronivelado por decorrugação FFT.

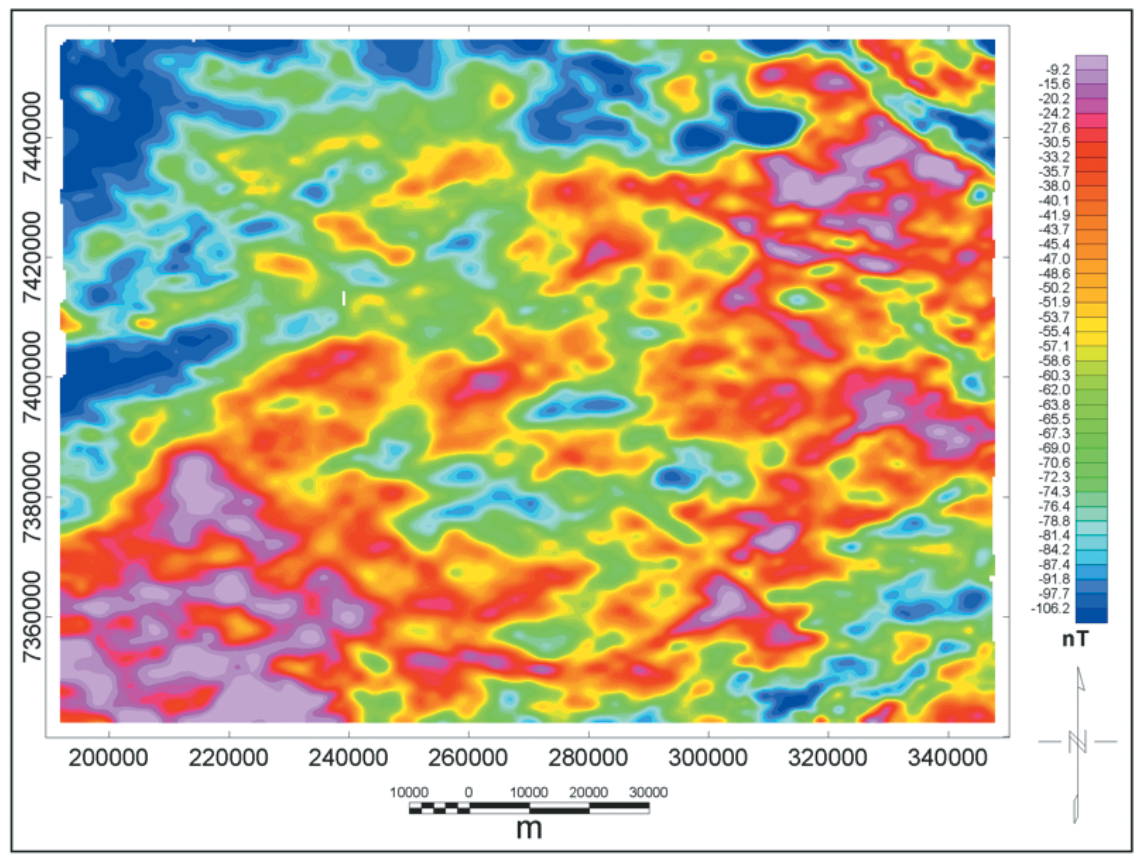

Figura 5 - Mapa magnético residual continuado para 1.000 m.

$1.000 \mathrm{~m}$, onde se pode observar tendências variadas, com predominância nas direções NW-SE e NE-SW, e anomalias mais relevantes localizadas na periferia da área, nos quadrantes NE e SE, principalmente.

\section{Fase do sinal analítico}

A fase ou inclinação do sinal analítico de ordem zero é definida pelo ângulo formado entre os vetores imaginário (derivada vertical) e real (derivadas horizontais) do sinal analítico e pode ser 


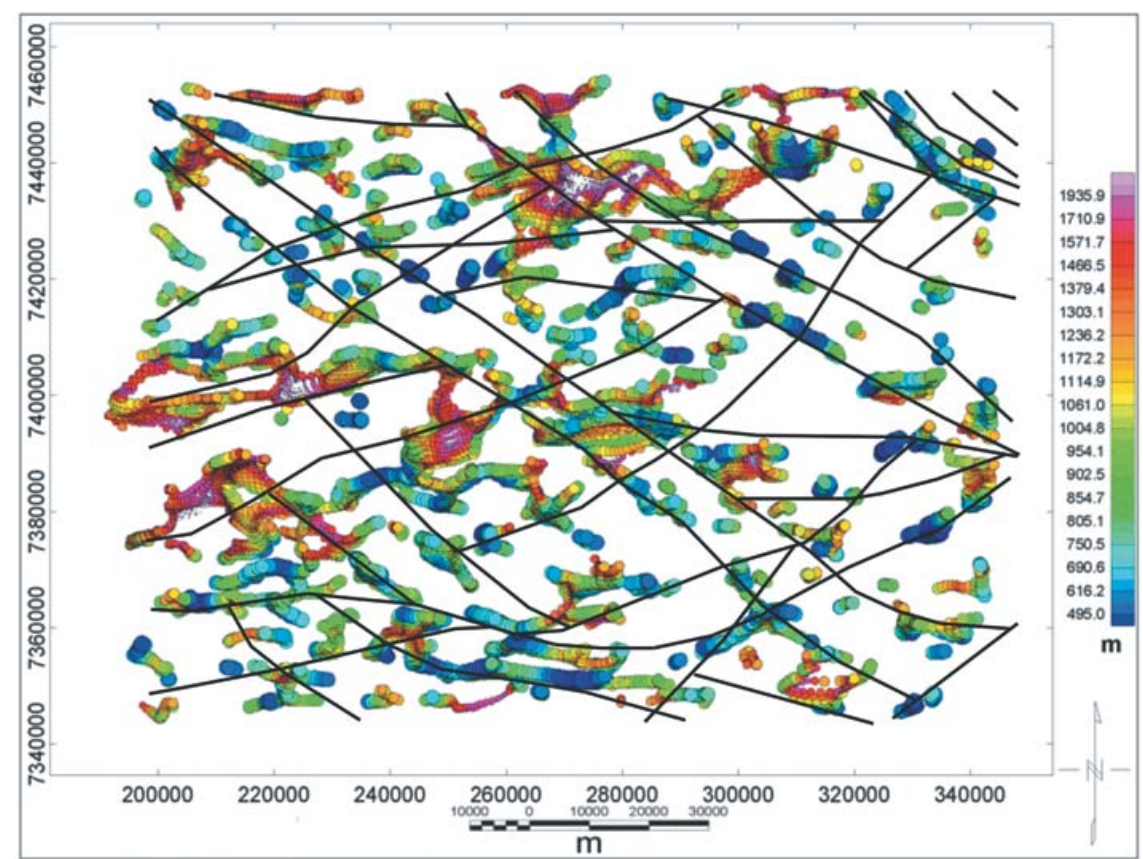

Figura 6 - Mapa de soluções de Euler do campo magnético continuado para $1.000 \mathrm{~m}$. (janela de busca de $10.000 \mathrm{~m}$ e índice estrutural 0,5).

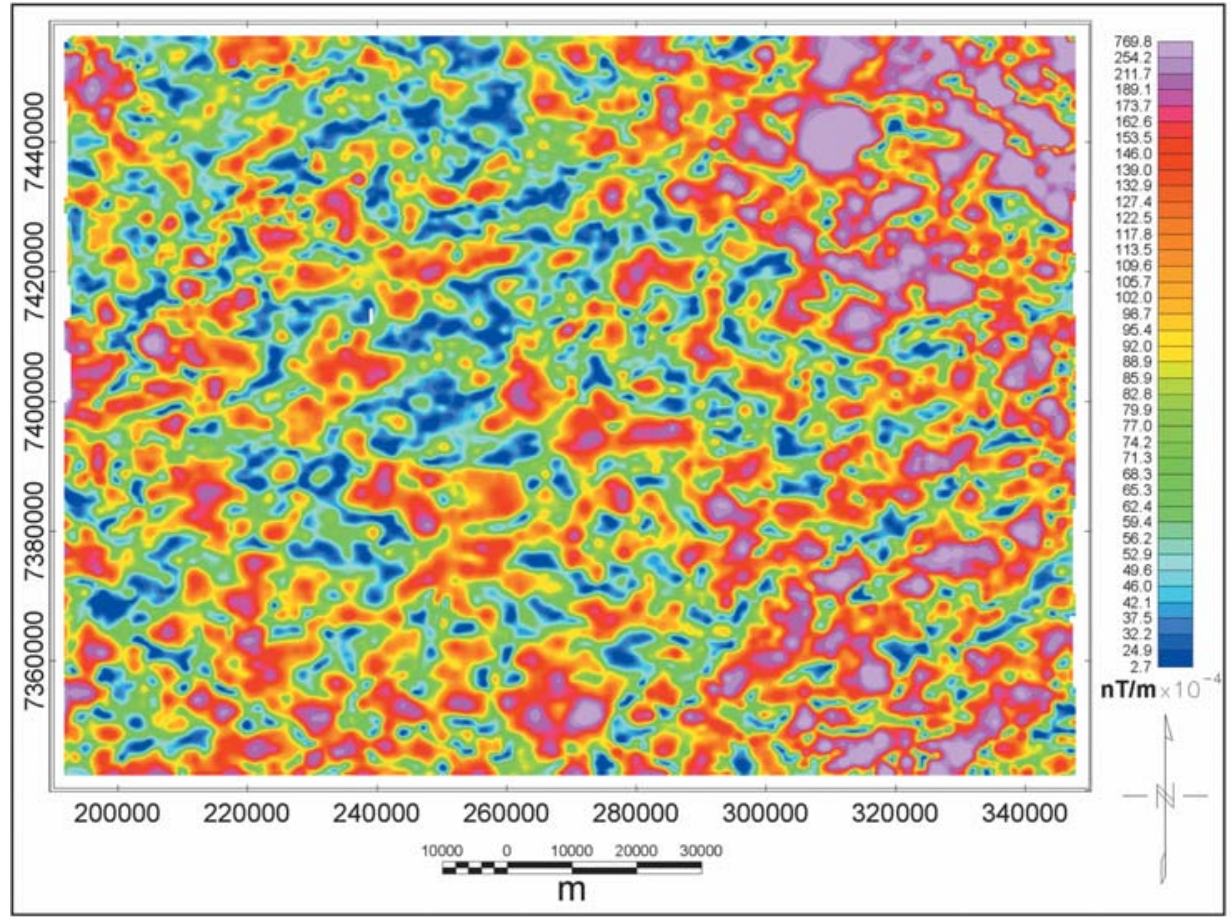

Figura 7 - Mapa da amplitude do sinal analítico de ordem zero do campo magnético continuado para $1.000 \mathrm{~m}$. 
expressa por:

$$
\theta(x, y, z)=\operatorname{arctg} \frac{\left(\frac{\partial M}{\partial z}\right)}{\left[\left(\frac{\partial M}{\partial x}\right)^{2}+\left(\frac{\partial M}{\partial y}\right)^{2}\right]^{1 / 2}}
$$

0 mapa da fase do sinal analítico do campo magnético continuado para $1.000 \mathrm{~m}$ é exibido na Figura 8, onde as anomalias são melhor delineadas, principalmente nas direções NW-SE e NE-SW.

\section{Gradiente horizontal total}

0 gradiente horizontal total de ordem zero é o vetor resultante das combinações das primeiras derivadas horizontais nas direções $x$ e $y$, dado pela equação abaixo (Milligan \& Gunn, 1997):

$$
h(x, y)=\left[\left(\frac{\partial M}{\partial x}\right)^{2}+\left(\frac{\partial M}{\partial y}\right)^{2}\right]^{1 / 2}
$$

0 mapa do gradiente horizontal total de ordem zero para a altura de vôo de 1.000 m é mostrado na Figura 9, 0 qual exibe tendências principalmente nas direções NW-SE e NE-SW.

\section{ARCABOUÇO MAGNÉTICO ESTRUTURAL}

A interpretação integrada dos produtos do processamento geofísico, antes apresentados (incluindo o mapa magnético residual, amplitude e fase do sinal analítico, gradiente horizontal e mapas de soluções de Euler), resultou no mapa do arcabouço magnéticoestrutural (Fig. 10). Tais estruturas possuem alta penetratividade nas rochas da Bacia do Paraná, com profundidades que ultrapassam os $3.500 \mathrm{~m}$. As estruturas orientadas nas direções NW-SE e E-W são bastante contínuas, enquanto as demais direções são frequentemente segmentadas, principalmente pelas primeiras.

A partir da porção central da área em direção ao quadrante NE, ocorre a predominância de estruturas orientadas na direção NWSE, coincidindo com a zona de falha Cândido de Abreu-Campo Mourão e a falha do Rio Alonzo. A Sul ocorre o lineamento de São Sebastião de Zalán et al. (1987), na forma de um arco voltado para Norte, presente em todos os mapas analisados, inclusive naqueles continuados para $4.000 \mathrm{~m}$, evidenciando a penetratividade destas estruturas em direção ao interior da bacia.

\section{ANÁLISE ESTRUTURAL DE SUPERFÍCIE E INTEGRAÇÃO COM DADOS DE SUBSUPERFÍCIE}

A análise estrutural de superfície foi baseada na interpretação de alinhamentos estruturais utilizando-se o modelo digital de elevação (MDE), composições multiespectrais de cenas Landsat 7 e na análise morfoestrutural da rede de drenagem. Os alinhamentos foram traçados separadamente sobre cada tema e posteriormente integrados no arcabouço estrutural da superfície dos arenitos do Grupo Caiuá, mostrado na Figura 11, sobreposto ao relevo sombreado do MDE.

Da mesma forma que os alinhamentos do embasamento, neste nível a direção com estruturas mais contínuas é NWSE, sendo que as demais direções são segmentadas por esta, ressaltando-se tendências dispostas segundo N-S. No extremo $\mathrm{NE}$, coincidindo com a falha do Rio Alonzo, foram mapeados cinco grandes alinhamentos paralelos de direção NW-SE.

A comparação entre os mapas estruturais do embasamento (Fig. 10) e da superfície do Grupo Caiuá (Fig. 11), revelou a coincidência de parte das estruturas mapeadas nos dois níveis de investigação, mostradas no mapa da Figura 12. Os alinhamentos mapeados constituem reflexo da herança tectônica do embasamento da Bacia Bauru, afetando também os arenitos do Grupo Caiuá.

No contexto de integração entre os dois níveis investigados, o número de estruturas mapeadas foi menor, porém notou-se a predominância nas direções NW-SE, NE-SW e E-W. A ausência de estruturas na direção N-S no arcabouço do embasamento, e conseqüentemente na integração dos dois níveis, deveu-se ao paralelismo com as linhas de vôo do levantamento aerogeofísico e ao processo de micronivelamento. A Sul, as tendências relacionadas ao lineamento de São Sebastião apresentam feição de arco voltado para Norte. Também estão presentes a zona de falha Cândido de Abreu-Campo Mourão, na porção central com direção NW-SE, e a falha do Rio Alonzo, no quadrante NE, com a mesma direção.

\section{CONTEXTO HIDROGEOLÓGICO}

As rochas que formam o Sistema Aqüífero Caiuá (SAC) são basicamente arenitos quartzosos a subarcosianos (feldspáticos) homogêneos, com intercalações de arenitos muito finos (Fernandes, 1992), porosos e permeáveis. A relação de contato entre os dois sistemas aqüíferos é mostrada por meio de um perfil esquemático $\mathrm{E}-\mathrm{W}$, da borda de ocorrência dos arenitos até 0 vale do rio Paraná (Fig. 13).

De acordo com os dados dos poços produtores de água da região, todos completados nos arenitos do SAC (Sanepar, 2002; Suderhsa, 2002), as profundidades de exploração variam desde menos de $30 \mathrm{~m}$ na porção leste, próximo ao contato com a Formação Serra Geral, até cerca de $230 \mathrm{~m}$, contígua ao rio Paraná, a oeste. 


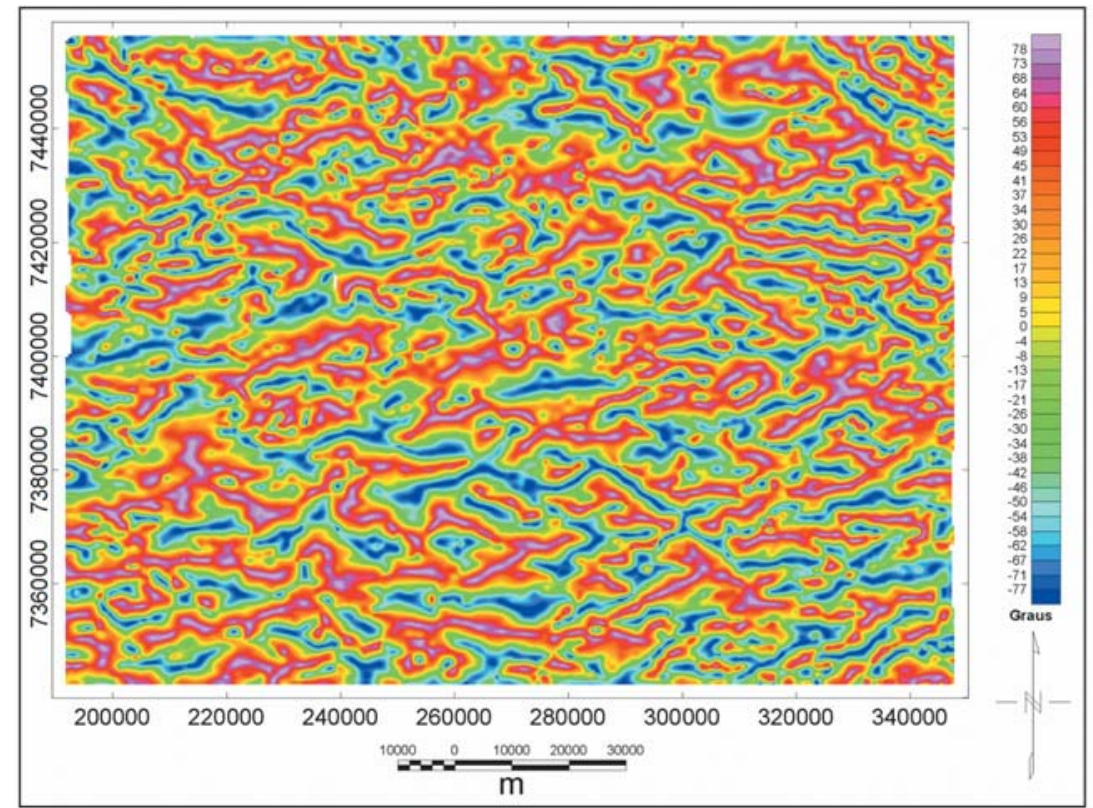

Figura 8 - Mapa da fase do sinal analítico de ordem zero do campo magnético continuado para $1.000 \mathrm{~m}$.

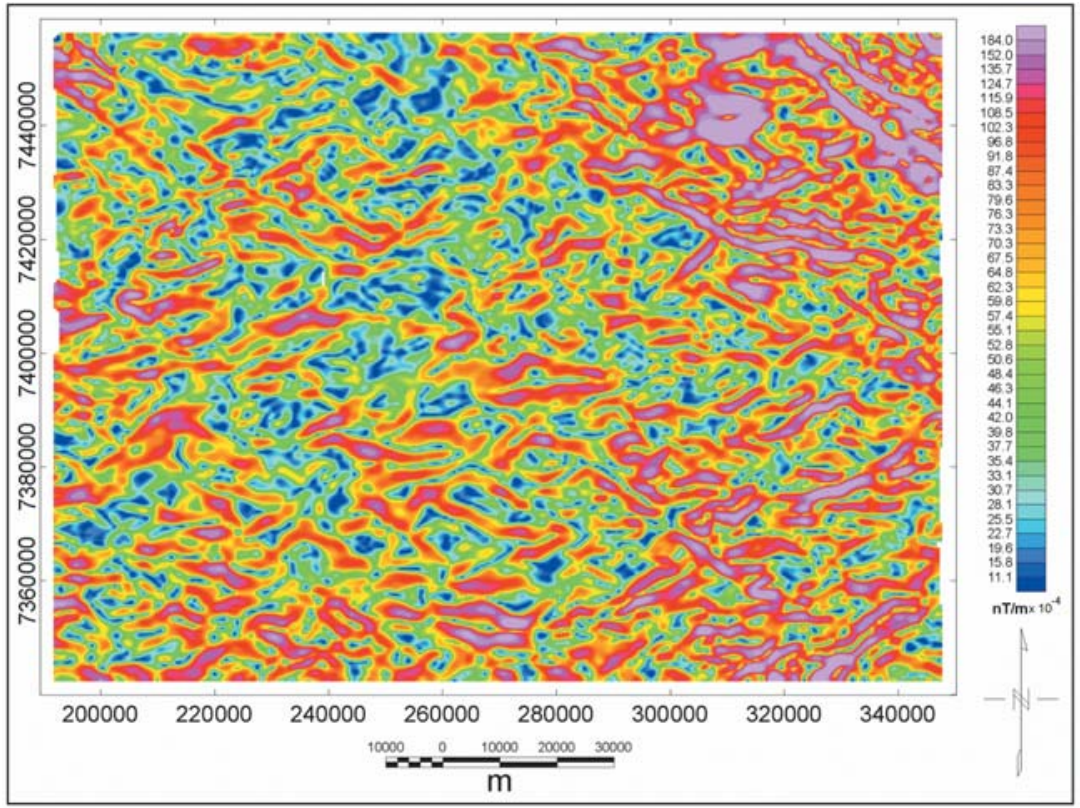

Figura 9 - Mapa do gradiente horizontal total de ordem zero do campo magnético continuado para 1.000 m.

Foram analisados a potenciometria, a vazão, a capacidade específica e os sólidos totais dissolvidos em 222 poços construídos no Sistema Aqüífero Caiuá. As análises hidroquímicas de 46 amostras (Celligoi, 2000), foram utilizadas na avaliação da distribuição espacial dos tipos químicos das águas subterrâneas da região.

\section{Potenciometria}

Em aqüíferos granulares livres a superfície potenciométrica apresenta correspondência regional com a superfície topográfica do terreno, conforme mostra o diagrama de dispersão da Figura 14, o qual relaciona as cotas altimétricas dos poços analisados e as correspondentes ao nível estático. Para a presente análise 


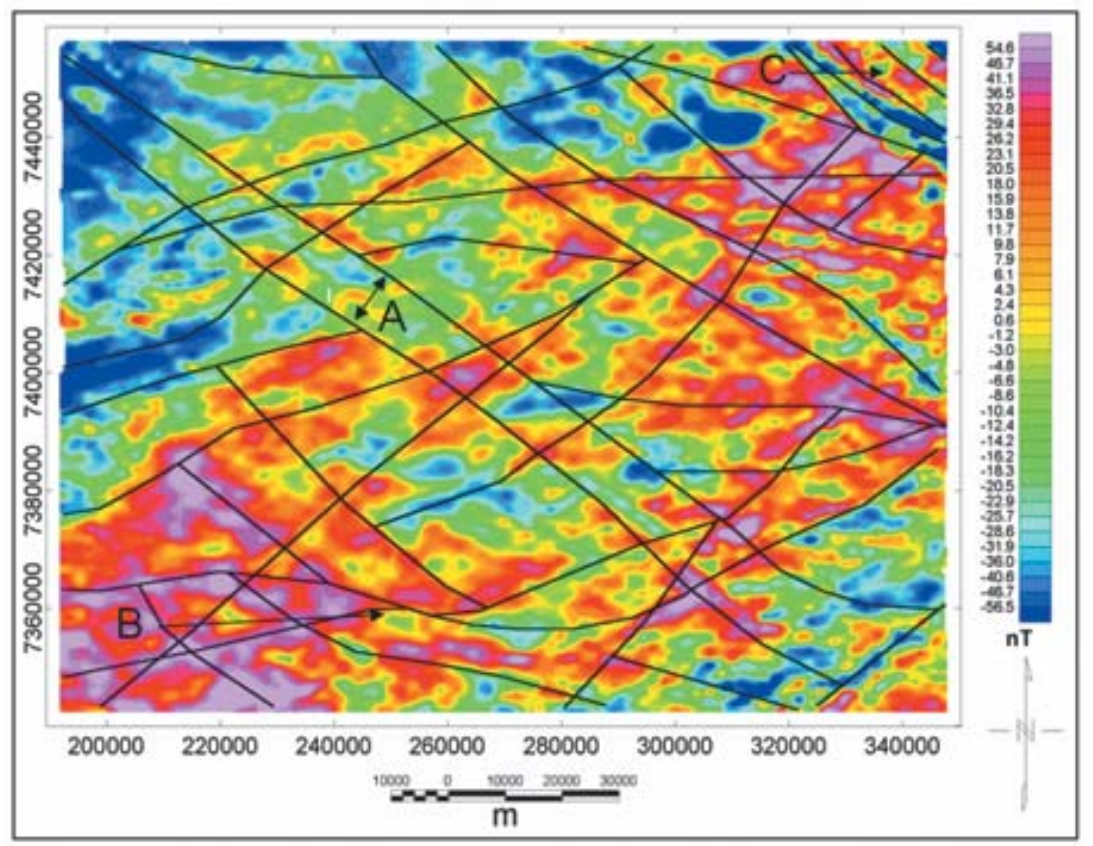

Figura 10 - Mapa do arcabouço magnético-estrutural do embasamento do Grupo Caiuá na área de estudo sobreposto ao mapa magnético residual micronivelado. A - Zona de Falha Cândido de Abreu - Campo Mourão; B - Lineamento de São Sebastião; C - Falha do Rio Alonzo.

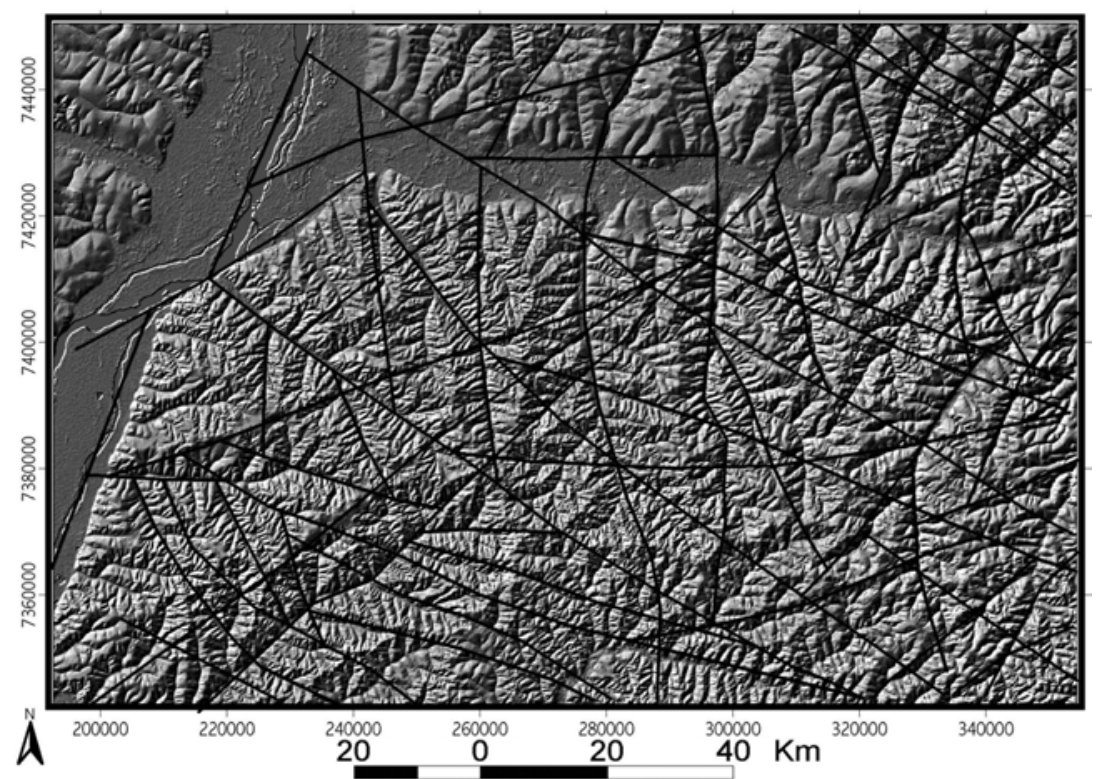

Figura 11 - Mapa do arcabouço estrutural de superfície dos arenitos do Grupo Caiuá, sobreposto ao MDE pseudoiluminado na direção N45E.

a aplicação de uma regressão linear resultou no coeficiente de correlação de 0,98.

Esta constatação permitiu a elaboração de um mapa da superfície potenciométrica da região mediante interpolação das co- tas do nível estático por krigagem anisotrópica com tendência externa do modelo digital de elevação (Bettú, 2004). Nesta interpolação a cota da superfície topográfica foi incluída na estimativa do valor da superfície potenciométrica para cada nó da malha. 


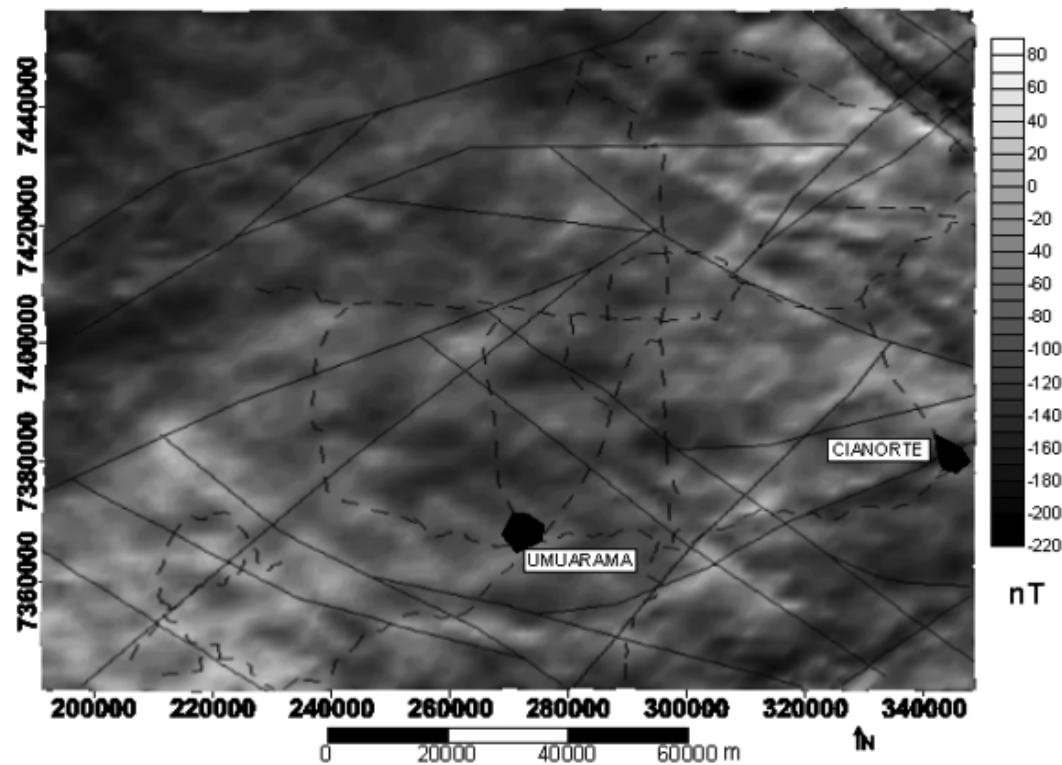

Figura 12 - Mapa do arcabouço estrutural comum da superfície do Grupo Caiuá e do seu embasamento, sobreposto ao mapa magnético residual pseudoiluminado na direção N45E.

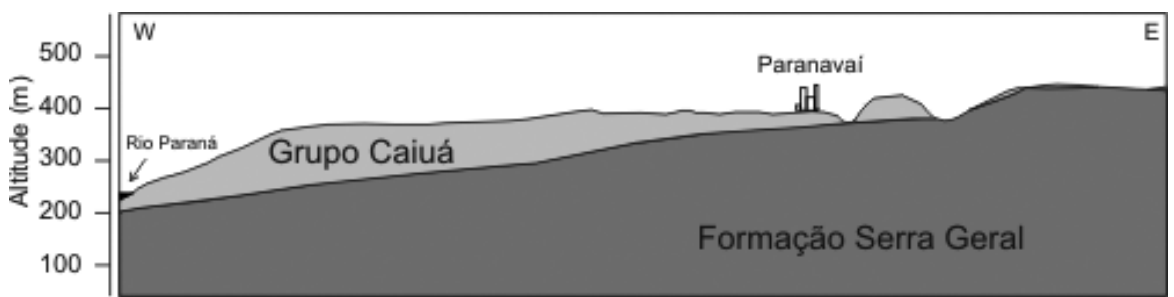

Figura 13 - Perfil esquemático mostrando as relações de contato entre o Grupo Caiuá e a Formação Serra Geral, modificado de Celligoi (2000).

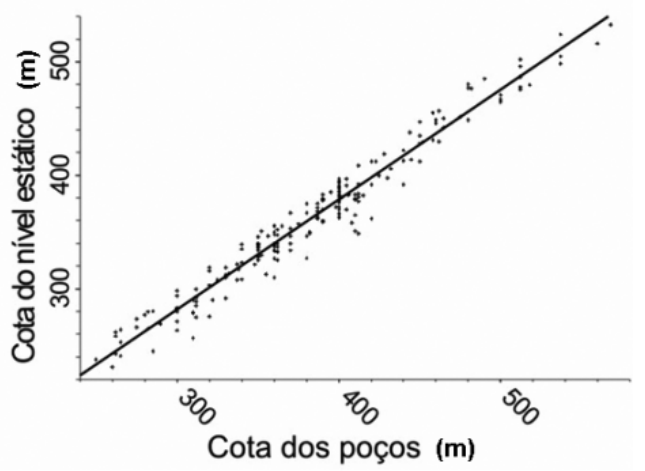

Figura 14 - Diagrama de dispersão confrontando as cotas dos poços e as do nível estático. Coeficiente de correlação $R=0,98$.

0 mapa potenciométrico resultante desta interpolação é mostrado na Figura 15. Os procedimentos adotados para estimar a superfície potenciométrica por krigagem com tendência externa do relevo são discutidos em Bettú \& Ferreira (2005).

\section{Vazão}

Foram analisados os dados de vazão obtidos durante os testes de bombeamento realizados durante a perfuração dos poços. A Tabela 1 mostra as estatísticas dos dados hidrogeológicos ava- 


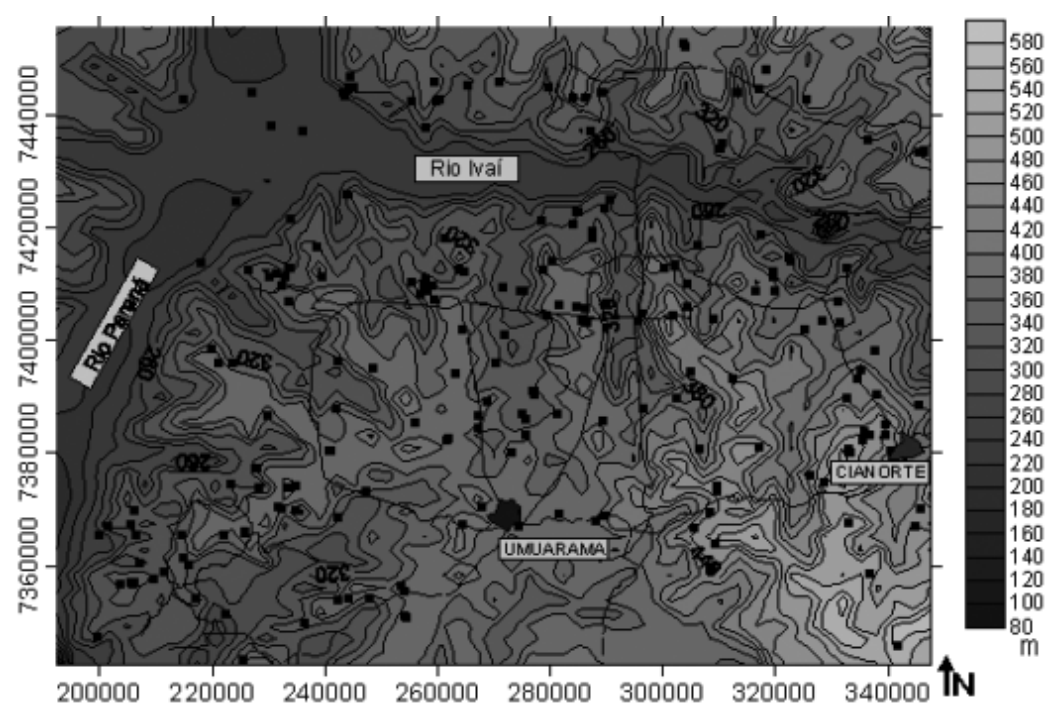

Figura 15 - Mapa de contorno da superfície potenciométrica construído através de krigagem com tendência externa do MDE (Bettú, 2004), indicando a localização dos poços.

liados. A vazão média dos poços é de $11,08 \mathrm{~m}^{3} / \mathrm{h}$, com máximo de $52,8 \mathrm{~m}^{3} / \mathrm{h}$.

Tabela 1 - Estatísticas hidrogeológicas dos poços analisados.

\begin{tabular}{|c|c|c|c|}
\hline & $\begin{array}{c}\text { Vazão } \\
\mathrm{m}^{3} / \mathrm{h}\end{array}$ & $\begin{array}{c}\text { Capacidade Específica } \\
\left(\mathrm{m}^{3} / \mathrm{h}\right) / \mathrm{m}\end{array}$ & $\begin{array}{c}\text { STD } \\
\mathrm{mg} / \mathrm{L}\end{array}$ \\
\hline Mínimo & 0,20 & 0,003 & 4,00 \\
\hline Média & 11,08 & 0,310 & 75,36 \\
\hline Máximo & 52,80 & 4,280 & 361,80 \\
\hline Desvio Padrão & 9,41 & 0,410 & 64,45 \\
\hline
\end{tabular}

A interpolação dos dados de vazão para uma malha regular de $3.100 \mathrm{~m} \times 2.260 \mathrm{~m}$, foi realizada através do algoritmo da mínima curvatura (Briggs, 1974) e o resultado é mostrado na Figura 16, sobreposto ao mapa de isópacas do Grupo Caiuá, de Fernandes (1992), e ao arcabouço estrutural comum, onde estão ressaltadas por hachuras as zonas mais produtivas, além da localização dos poços.

Observa-se neste mapa nítidas relações espaciais entre as estruturas mapeadas e as zonas com vazões elevadas. Tais estruturas normalmente limitam blocos romboédricos com altas vazões, porém a ocorrência de cruzamento destas feições também foi interpretada como responsável por altas produtividades.

\section{Capacidade específica}

A capacidade específica é a razão entre a vazão e o rebaixamento do nível dinâmico, quando o poço está sendo bombeado, e reflete a capacidade de fornecimento de água de um determinado poço frente ao rebaixamento do nível dinâmico. Conforme mos- trado na Tabela 1, a capacidade específica tem valor médio de 0,31 $\left(\mathrm{m}^{3} / \mathrm{h}\right) / \mathrm{m}$ e máximo de $4,28\left(\mathrm{~m}^{3} / \mathrm{h}\right) / \mathrm{m}$.

A Figura 17 mostra a distribuição da capacidade específica, construída através do algoritmo da curvatura mínima, já mencionado. Na mesma figura são apresentados 0 arcabouço estrutural comum aos dois níveis de investigação, as isópacas do Grupo Caiuá, a localização dos poços estudados e as zonas de maior capacidade específica (hachuras). A opção por avaliar a distribuição espacial da capacidade específica se deu porque, ao contrário da vazão, esta variável independe do equipamento instalado, apresentando maior correspondência aos fatores intrínsecos do reservatório.

\section{Sólidos totais dissolvidos (STD)}

Os teores de sólidos totais dissolvidos possuem relação direta com a composição mineralógica da rocha-reservatório e com 0 tempo de percolação/residência das águas subterrâneas no interior do sistema. Celligoi (2000), ao estudar todo o Sistema Aqüífero Caiuá (SAC) no estado do Paraná, comparou os teores de STD, em média de 75,4 mg/L, com o teor médio do Sistema Aqǘfero Serra Geral (SASG), de 212,0 mg/L. Esta característica é decorrente da recarga do primeiro sistema, que ocorre de forma direta (pouco tempo de residência), em função da grande permeabilidade das rochas. Outro fator responsável pelos baixos índices de STD nas águas do SAC é a composição das rochas do Grupo Caiuá na região, onde predominam fácies areníticas quartzosas (insolúveis nas condições normais de temperatura e pressão do 


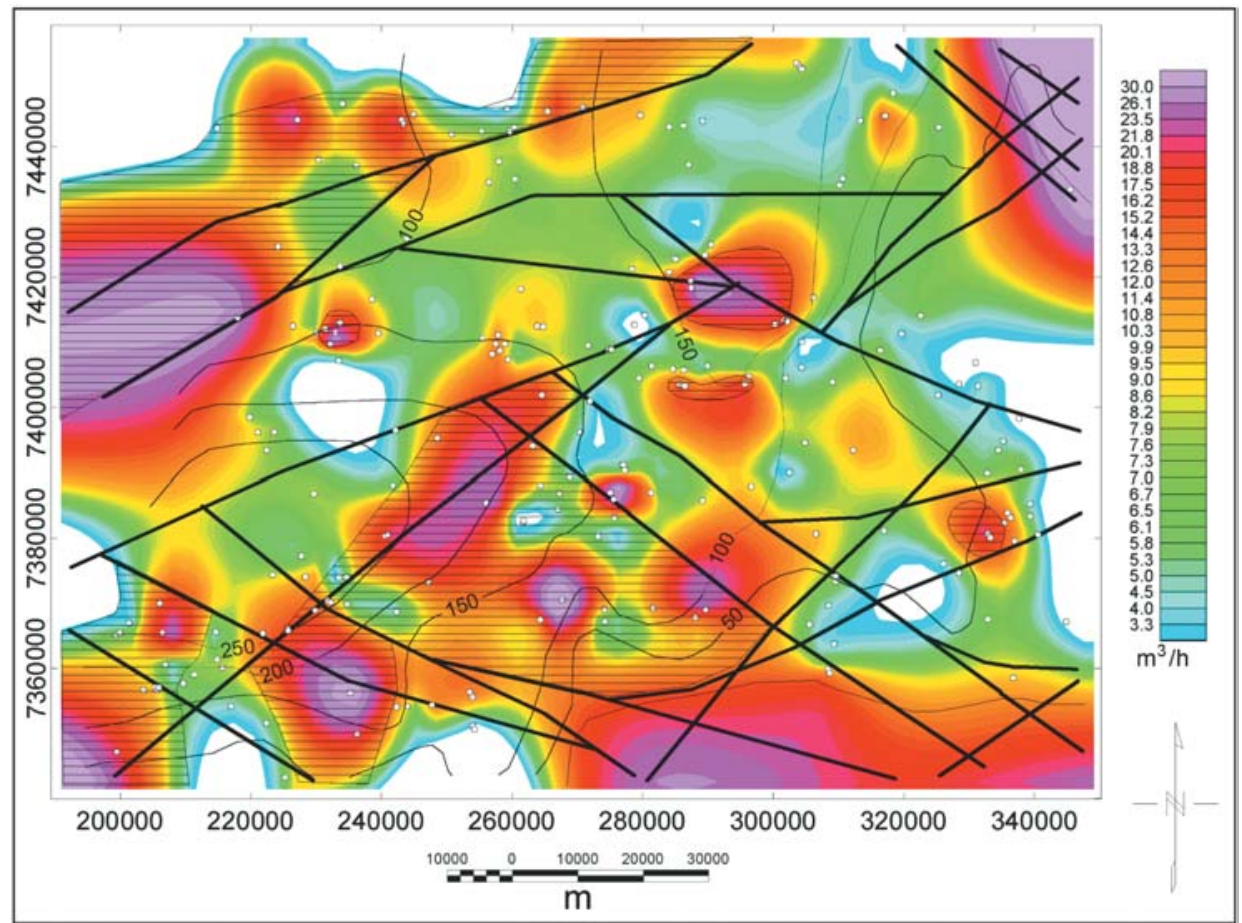

Figura 16 - Mapa de vazão incluindo o arcabouço estrutural comum, as isópacas do Grupo Caiuá e a localização dos poços, exibindo as zonas mais produtivas (hachuras).

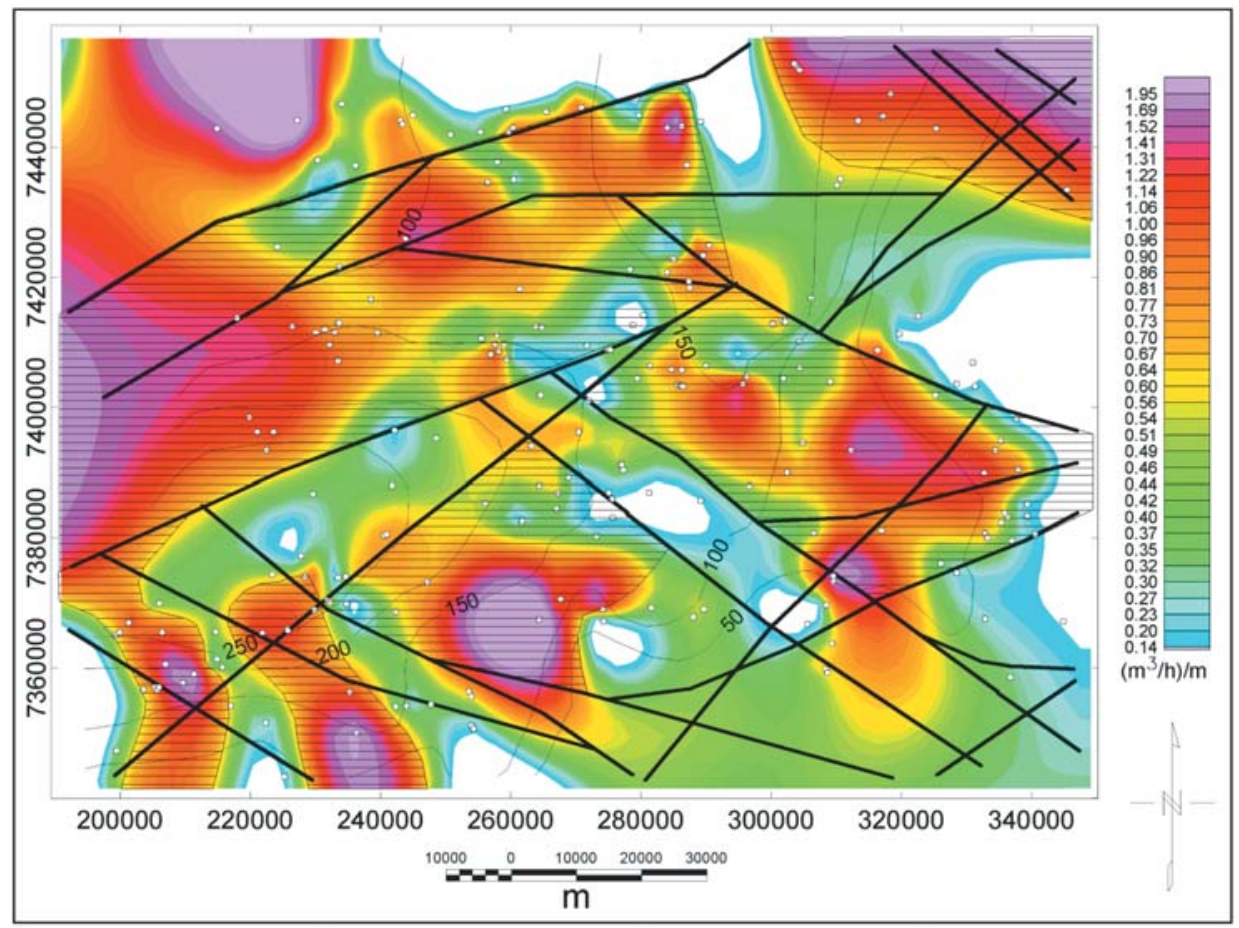

Figura 17 - Mapa de capacidade específica incluindo o arcabouço estrutural comum, as isópacas do Grupo Caiuá e a localização dos poços, exibindo as zonas mais produtivas (hachuras). 
aqüífero), com quantidades menores de feldspatos (microclínio) e argilominerais, estes últimos responsáveis pelo quimismo das águas subterrâneas do SAC.

As estatísticas dos valores de STD para as águas do SAC são mostradas na Tabela 1, com índices enquadrados no padrão de potabilidade recomendado pela Organização Mundial da Saúde (OMS, 1998) e compatíveis com os resultados de Celligoi (2000), os quais indicam teores anômalos, acima de $200 \mathrm{mg} / \mathrm{L}$, interpretados como contribuições provenientes do Sistema Aqüífero Serra Geral (Bettú, 2004).

0 mapa dos teores de STD (Fig. 18) foi elaborado por interpolação (curvatura mínima) com células da malha já definida e os valores negativos, decorrentes do processo de estimativa, foram suprimidos. Também pode-se observar nesse mapa as isópacas do Grupo Caiuá, o arcabouço estrutural comum aos dois níveis de investigação e o posicionamento dos poços. As zonas hachuradas refletem os blocos com teores mais elevados de STD, as quais estão relacionadas com tratos de entrada de água do SASG no interior do SAC.

\section{Hidroquímica}

Este tópico visou avaliar a espacialização dos tipos químicos das águas da região, com base no conteúdo catiônico das amostras coletadas em poços produtores completados no SAC. As 46 amostras utilizadas, obtidas em Celligoi (2000), contemplaram 0 limite de $10 \%$ de erro de balanço iônico, cujas estatísticas são indicadas na Tabela 2. A classificação hidroquímica foi centrada no conteúdo dos quatro cátions maiores das águas naturais do SAC: $\mathrm{Ca}^{++}, \mathrm{Na}^{+}, \mathrm{K}^{+}$e $\mathrm{Mg}^{++}$.

Tabela 2 - Resultados do balanço iônico.

\begin{tabular}{|l|c|}
\hline Número de amostras & 46 \\
\hline Erro mínimo & $0,7 \%$ \\
\hline Média & $1,72 \%$ \\
\hline Erro máximo & $8,6 \%$ \\
\hline Desvio padrão & 1,15 \\
\hline
\end{tabular}

Segundo Rosa Filho et al. (1987), as águas típicas do SASG são classificadas como bicarbonatadas cálcicas, com teores elevados de $\mathrm{Ca}^{++}$, provenientes da solubilização de carbonatos, enquanto os teores de $\mathrm{Na}^{+}$e $\mathrm{Mg}^{++}$decorrem da solubilização dos feldspatos (plagioclásios) e dos piroxênios, respectivamente.

A homogeneidade litológica do Grupo Caiuá na área de estudo é reflexo da composição mineralógica do SAC, formado basicamente por quartzo, feldspatos potássicos (microclínio) e argilominerais (Rosa Filho et al., 1987). Uma vez que os argilominerais estão presentes em pequenas quantidades e que 0 quartzo é insolúvel em condições normais de temperatura e pressão no meio natural, as águas deste sistema aqüífero tornam-se enriquecidas em $\mathrm{K}^{+}$, provenientes da solubilização dos feldspatos potássicos do SAC.

Por possuir carga iônica sensivelmente reduzida, as águas do SAC são altamente susceptíveis à contaminação proveniente de águas do SASG. Assim, por menor que seja a quantidade de cátions $\left(\mathrm{Ca}^{++}, \mathrm{Na}^{+}, \mathrm{Mg}^{++}\right)$proveniente dos basaltos da Formação Serra Geral e que entrem em contato com as águas do SAC, rapidamente estas águas adquirem características químicas do SASG (Rosa Filho et al., 1987). Desta forma, as águas predominantemente bicarbonatadas potássicas, típicas do SAC, são mescladas com águas bicarbonatadas cálcicas do SASG, através de ascensão vertical por fraturas e em condições potenciométricas favoráveis, caracterizando zonas de conectividade hidráulica.

0 diagrama de Piper, construído com as amostras disponíveis (Fig. 19), foi modificado conforme sugerido em Rosa Filho et al. (1987) e A.V.L. Bittencourt (comunicação verbal). No diagrama original de Piper, os vértices dos cátions são ocupados por $\mathrm{Mg}^{++}, \mathrm{Ca}^{++} \mathrm{e} \mathrm{Na}^{+}+\mathrm{K}^{+}$, os quais foram alterados para $\mathrm{Na}^{+}, \mathrm{K}^{+}$ e $\mathrm{Mg}^{++}+\mathrm{Ca}^{++}$. A opção de desvincular os cátions $\mathrm{Na}^{+}$e $\mathrm{K}^{+}$, conseqüentemente agrupando $\mathrm{Mg}^{++} \mathrm{e} \mathrm{Ca}$, visou realçar as características hidroquímicas que discriminam os dois sistemas aqüíferos em questão, principalmente 0 isolamento do $\mathrm{K}^{+}$, típico das águas do SAC.

Nesta classificação apenas 14 amostras, das 46 avaliadas, revelaram características hidroquímicas típicas do SAC, Iocalizadas próximo ao vértice do $K^{+}$na Figura 19 , enquanto as demais denotam contribuições de águas dos basaltos da Formação Serra Geral, através do enriquecimento dos demais cátions analisados $\left(\mathrm{Na}^{+}, \mathrm{Mg}^{++}\right.$e Ca $\left.{ }^{++}\right)$.

Visando avaliar a distribuição espacial dos cátions frente ao arcabouço estrutural proposto, Bettú (2004) sugeriu um mapa de composição ternária RGB, utilizando o mesmo padrão do diagrama de Piper modificado. Esta composiçãa foi construída com células de $5.000 \mathrm{~m}$ e elipse de busca de $12.000 \mathrm{~m}$, com base na fusão de malhas representativos de cada um dos vértices. A utilização da elipse de busca serviu para reduzir a inferência da interpolação, realizada pelo algoritmo da curvatura mínima.

A Figura 20 mostra o mapa de composição ternária de Bettú (2004). As porções hachuradas indicam a predominância de águas com características hidroquímicas do SAC, enquanto que as demais zonas são interpretadas como decorrentes de diferentes taxas de mistura das águas dos sistemas aqüíferos considerados. É perceptível a correspondência entre estes núcleos ricos em $\mathrm{K}^{+}$ e as maiores espessuras do Grupo Caiuá. 


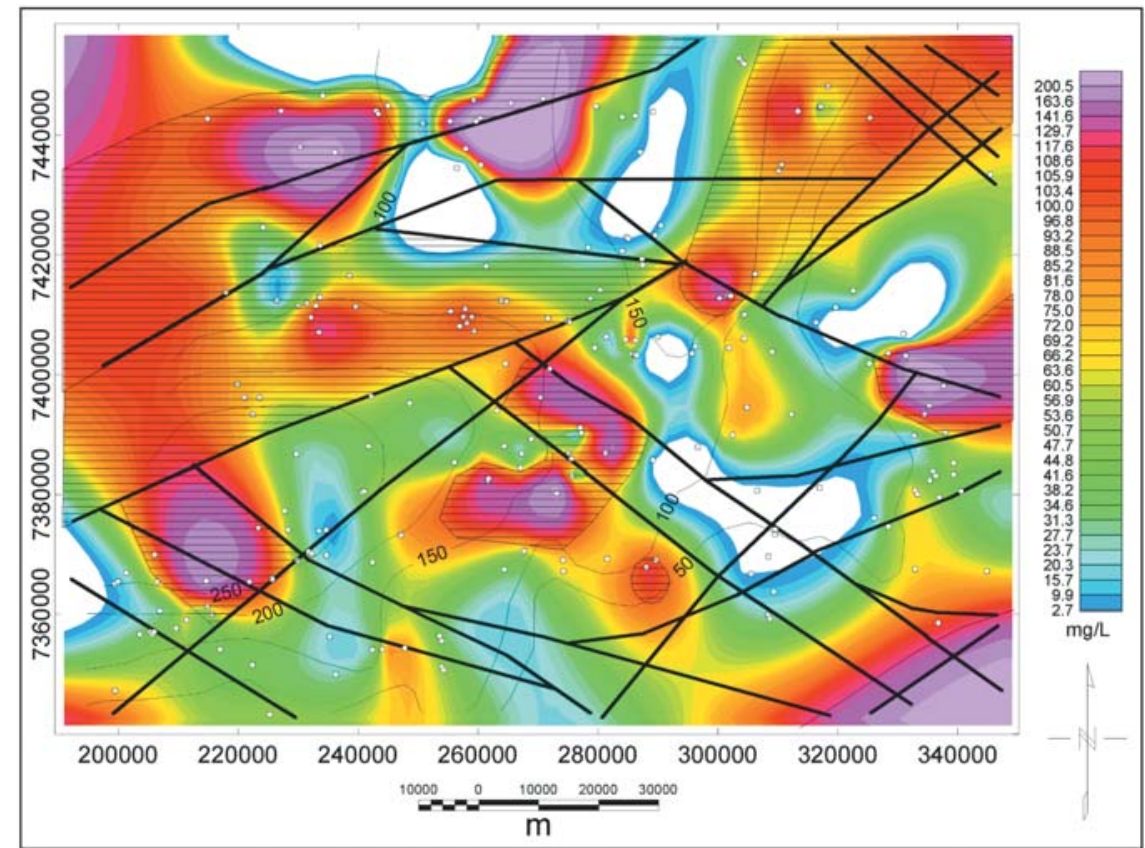

Figura 18 - Mapa de teores de STD incluindo o arcabouço estrutural comum, as isópacas do Grupo Caiuá e a localização dos poços, exibindo as zonas com maiores teores (hachuras).

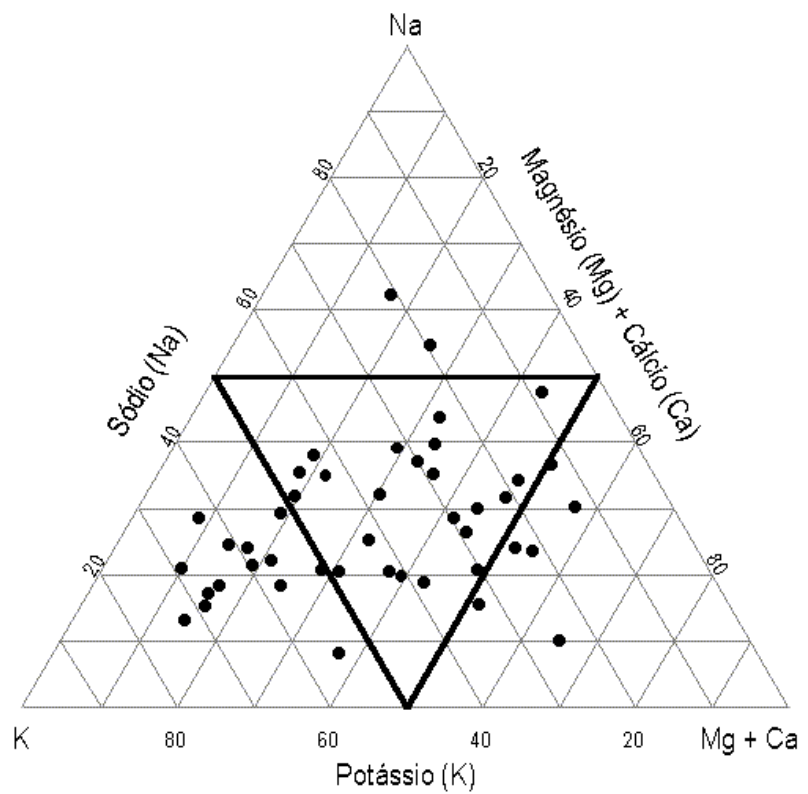

Figura 19 - Diagrama modificado de Piper referente aos poços completados no Sistema Aqüífero Caiuá. Dados de Celligoi (2000).

\section{CONCLUSÕES}

0 processamento e subseqüente interpretação dos dados aerogeofísicos mostrou eficácia no delineamento do arcabouço estrutural-magnético e nas estimativas de profundidades das fon- tes do embasamento da Bacia Bauru no noroeste do estado do Paraná, uma vez que é grande o contraste de susceptibilidade magnética entre os arenitos do Grupo Caiuá e os basaltos da Formação Serra Geral. Os resultados da Deconvolução de Euler revelaram que as estruturas mapeadas atingem até $3.500 \mathrm{~m}$ 


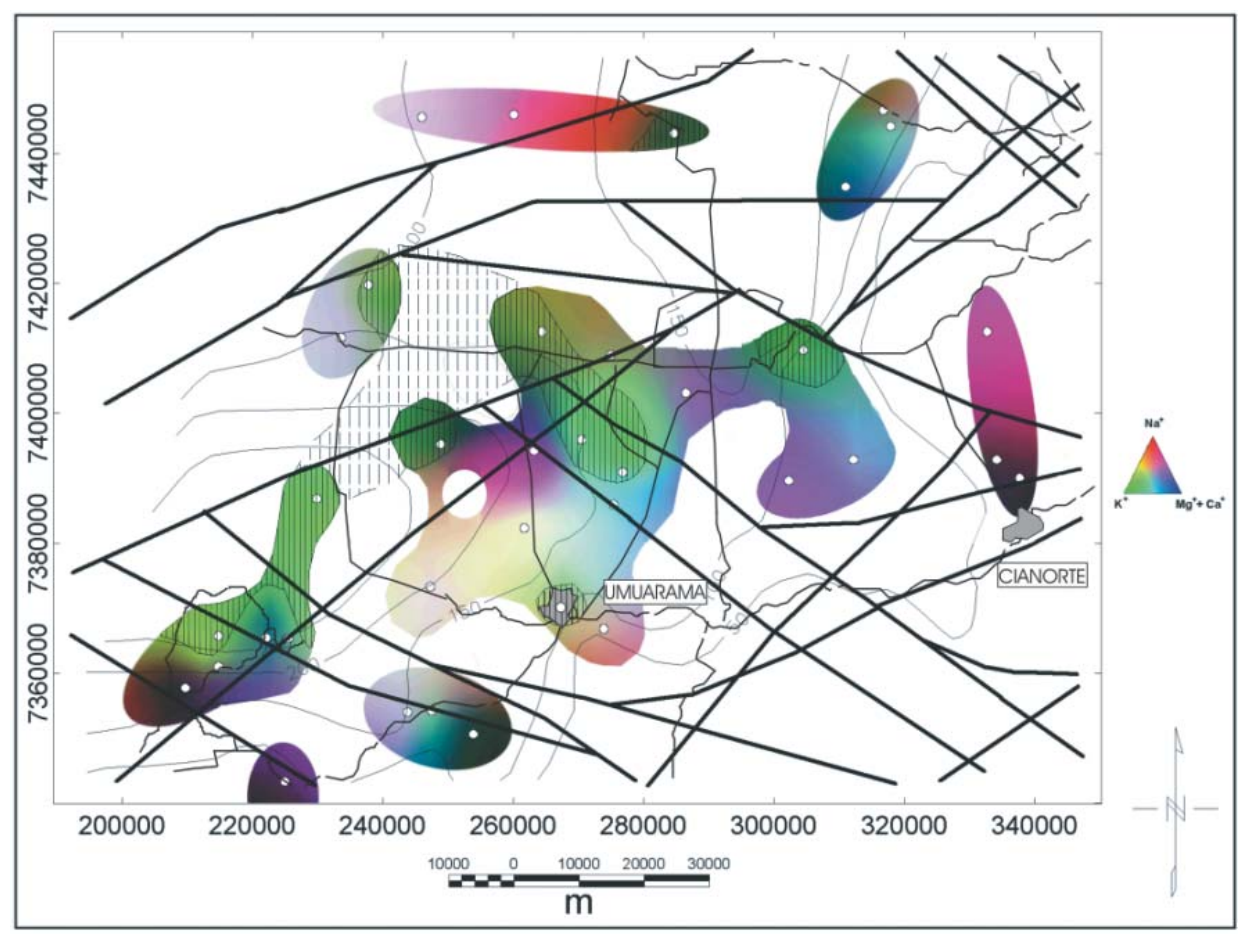

Figura 20 - Mapa de composição ternária $\mathrm{R}\left(\mathrm{Na}^{+}\right)-\mathrm{G}\left(\mathrm{K}^{+}\right)-\mathrm{B}\left(\mathrm{Mg}^{++}+\mathrm{Ca}^{++}\right)$dos poços completados no Sistema Aqüífero Caiuá, indicando as áreas de composição potássica (zonas hachuradas), o arcabouço estrutural comum e as isópacas do Grupo Caiuá.

de profundidade, alcançando provavelmente 0 embasamento da Bacia do Paraná.

A interpretação dos alinhamentos estruturais realizada de forma independente sobre os mapas do modelo digital de elevação (MDE), imagens Landsat 7 e da rede de drenagem, posteriormente harmonizados, resultou em um modelo consistente do arcabouço estrutural da superfície do Grupo Caiuá.

A coincidência de algumas feições mapeadas nos dois níveis de investigação, permitiu revelar uma complexa trama estrutural tanto nos basaltos da Formação Serra Geral (embasamento da Bacia Bauru) quanto nos arenitos do Grupo Caiuá. 0 arcabouço estrutural integrado delineou estruturas nas direções NW-SE, NE-SW e E-W. A ausência de lineamentos magnéticos na direção $\mathrm{N}-\mathrm{S}$, bem caracterizados na análise multitemática de superfície, pode ser atribuída ao paralelismo com as linhas de vôo e à aplicação do micronivelamento na direção N-S.

As estruturas mapeadas resultam de esforços tectônicos atuantes durante o fim do Cretáceo e o Cenozóico (pós-deposicionais), que causaram a compartimentação dos sistemas aqüíferos e a conseqüente geração de zonas de mesclagem hidráulica entre 0 SAC e 0 SASG, utilizando descontinuidades herdadas do embasamento.
Por meio da análise da distribuição espacial das variáveis hidrogeológicas (vazão e capacidade específica) e hidroquímicas (STD e cátions - $\mathrm{Na}^{+}, \mathrm{K}^{+}, \mathrm{Mg}^{++}$e $\mathrm{Ca}^{++}$), a compartimentação do SAC e a presença de zonas de entrada de água do SASG no primeiro ficou evidente. Verificou-se que as maiores vazões e capacidades específicas são delimitadas ora por blocos romboédricos balizados por estruturas nas direções NW-SE e NE-SW, ora estão localizadas em grandes estruturas ou em seus cruzamentos.

Do mesmo modo, observou-se boa correlação entre a distribuiçãa espacial dos teores de STD e 0 arcabouço estrutural integrado. Assim, foram delineados maiores teores de STD nos extremos noroeste, sudoeste, leste e no centro da área de estudo, justamente em tratos onde os arenitos do Grupo Caiuá são mais delgados e as águas do SAC ficam mais próximas às águas do SASG.

0 diagrama de Piper modificado mostrou que apenas 30\% das amostras apresentam caráter predominantemente potássico, apesar de todos os poços analisados terem suas entradas de água no interior dos arenitos do Grupo Caiuá. Esta característica hidroquímica do Sistema Aqǘfero Caiuá (SAC) é decorrente da contribuição dos feldspatos potássicos do Grupo Caiuá (microclínio), principais fornecedores de $\mathrm{K}^{+}$para 0 SAC. 0 restante 
das amostras exibe contribuições variadas dos demais cátions $\left(\mathrm{Na}^{+}, \mathrm{Mg}^{++}+\mathrm{Ca}^{++}\right)$, denotando contaminação, em graus variados, das águas do SAC pelo SASG. Uma vez que as rochas da Formação Rio Paraná são dominantemente quartzo arenitos, os teores de $\mathrm{K}^{+}$encontrados provavelmente provém da Formação Goio Erê, aflorante na porção leste da área, que tem maior imaturidade mineralógica, o que implica maior freqüência de arenitos subarcosianos.

A espacialização do diagrama de Piper, modificado da composição ternária RGB de Bettú (2004), permitiu avaliar 0 comportamento das variáveis hidroquímicas em correspondência ao arcabouço estrutural integrado. Desta forma foram delineados compartimentos onde as águas são predominantemente potássicas, no centro-oeste da área, assim como estabelecer suas relações com as maiores espessuras do Grupo Caiuá. As demais áreas representam contaminações do SAC pelo SASG, através de diferentes taxas de mistura, sugerindo zonas de conectividade hidráulica dos mencionados sistemas aqüíferos, através de fraturas e em condições potenciométricas favoráveis. Nestes tratos os cátions $\mathrm{Na}^{+}$e $0 \mathrm{Mg}^{++}$são decorrentes da dissolução de plagioclásios sódicos e dos piroxênios, respectivamente, ambos provenientes dos basaltos da Formação Serra Geral. Já o cátion $\mathrm{Ca}^{++}$ presente nestas áreas, pode ser interpretado como originário das águas do SASG (dissolução de calcitas) e/ou da cimentação carbonática que ocorre nas porções basais do Grupo Caiuá.

\section{AGRADECIMENTOS}

Os autores agradecem a Companhia de Saneamento do Paraná (Sanepar) e a Superintendência de Desenvolvimento de Recursos Hídricos e Saneamento Ambiental (Suderhsa) pela cessão dos dados hidrogeológicos utilizados na pesquisa; ao Projeto Modres, do Departamento de Geologia da UFPR, pela cessão das imagens orbitais; à Petrobras pela cessão dos dados aerogeofísicos; ao Conselho Nacional de Desenvolvimento Científico e Tecnológico - CNPq, pela concessão de Bolsa de Mestrado, Fundo Setorial CT-HIDR0, processo n. 132060/2002-7 e aos revisores da Revista Brasileira de Geofísica pelas valiosas contribuições.

\section{REFERÊNCIAS}

ALMEIDA FFM. 1986. Distribuição regional e relações tectônicas do magmatismo pós-paleozóico no Brasil. Revista Brasileira de Geociências, São Paulo, 16(4): 325-349.

BETTÚ DF. 2004. Conectividade e compartimentação dos Sistemas Aqǘferos Caiuá e Serra Geral no noroeste do estado do Paraná Dissertação (Mestrado em Geologia Exploratória) - Departamento de
Geologia, Universidade Federal do Paraná, Curitiba, 107 p.

BETTÚ DF \& FERREIRA FJF. 2005. Modelos da superfície potenciométrica do Sistema Aqüífero Caiuá no noroeste do estado do Paraná: comparação entre krigagem ordinária e krigagem com tendência externa do modelo numérico do terreno. Águas Subterrâneas, 19(2): (no prelo)

BRIGGS IC. 1974. Machine contouring using minimum curvature. Geophysics, 39(1): 39-48

CELLIGOI A. 2000. Hidrogeologia da Formação Caiuá no estado do Paraná. São Paulo. Tese (Doutorado em Recursos Minerais e Hidrogeologia) - Instituto de Geociências, Universidade de São Paulo, São Paulo, $95 \mathrm{p}$.

CPRM. Companhia de Pesquisa de Recursos Minerais. 2001. Geologia, tectônica e recursos minerais do Brasil: sistema de informações geográficas - SIG. Mapas na escala 1:250.000. Brasília. 04 CDs-ROM.

FERNANDES LA. 1992. A cobertura cretácea suprabasáltica no Paraná e Pontal do Paranapanema (SP): os grupos Bauru e Caiuá. São Paulo. Dissertação (Mestrado em Geologia Sedimentar) - Instituto de Geociências, Universidade de São Paulo, São Paulo, 129 p.

FERNANDES LA \& COIMBRA AM. 1996. A Bacia Bauru (Cretáceo Superior, Brasil). Anais da Academia Brasileira de Ciências, 68(2): 195-205.

FERREIRA FJF. 1982a. Alinhamentos estruturais - magnéticos da região centro-oriental da Bacia do Paraná: reavaliação da potencialidade e prospectividade em hidrocarbonetos. São Paulo: Consórcio CESP-IPT Paulipetro, p. 144-166.

FERREIRA FJF. 1982b. Integração de dados aeromagnéticos e geológicos: configuração e evolução tectônica do Arco de Ponta Grossa. São Paulo. Dissertação (Mestrado em Geologia Geral e de Aplicação) - Instituto de Geociências, Universidade de São Paulo, São Paulo, 170 p.

MILLIGAN P \& GUNN PJ. 1997. Enhancement and presentation of airborne geophysical data. AGSO Journal of Australian Geology \& Geophysics, 17(2): 63-75.

MINTY BRS. 1991. Simple micro-leveling for aeromagnetical data. Exploration Geophysics, 22: 591-592.

NABIGHIAN MN. 1972. The analytic signal of two-dimensional magnetic bodies with polygonal cross-section: its properties and use for automated anomaly interpretation. Geophysics, 37: 507-517.

NABIGHIAN MN. 1974. Additional comments on the analytic signal of two-dimensional magnetic bodies with polygonal cross-section. Geophysics, 39: 85-92.

OMS. Organização Mundial de Saúde. 1998. Guidelines for drinkingwater quality, 2nd ed. Addendum to Vol. 2. Health criteria and other supporting information. Geneva, World Health Organization. Disponível em: < http: // www.who.int / docstore / water_sanitation_health / GDWQ / Updating/draftguidel/draftchap87.htm>. Acesso em: 21 jun. 2004. 
PETROBRAS. Petróleo Brasileiro S.A. 1980. Projeto Aerogeofísico Rio Ivaí. Consórcio CESP/IPT, Paulipetro (dados digitais).

ROSA FILHO EF da. 1982. Uma análise sobre a produtividade dos poços tubulares no Aqüífero Caiuá - região noroeste do estado do Paraná. Dissertação (Mestrado em Geologia) - Centro de Tecnologia, Universidade Federal de Pernambuco, Recife, $p$.

ROSA FILHO EF da, SALAMUNI R \& BITTENCOURT AVL. 1987. Contribuição ao estudo das águas subterrâneas nos basaltos no estado do Paraná. Boletim Paranaense de Geociências, 37: 22-52.

SANEPAR. Companhia de Saneamento do Paraná. 2002. Banco de dados hidrogeológicos (arquivo digital).

SOARES PC. 1991. Tectônica sinsedimentar cíclica na Bacia do Paraná: controles. Tese (Professor Titular) - Universidade Federal do Paraná, Curitiba, $148 p$.

SUDERHSA. Superintendência de Desenvolvimento de Recursos Hídricos e Saneamento Ambiental. 2002. Banco de dados hidrogeológicos (arquivo digital).

THOMPSON DT. 1982. EULDPH: A new technique for making computerassisted depth estimates from magnetic data. Geophysics, 47: 31-37.

ZALÁN PV, WOLFF S, CONCEIÇÃO JCJ, ASTOLF MAM, VIEIRA IS, APPI VT \& ZANOTTO OA. 1987. Tectônica e sedimentação da Bacia do Paraná. In: Simpósio sul-brasileiro de geologia, III, Curitiba: Sociedade Brasileira de Geologia, 1: 441-473.

\section{NOTAS SOBRE OS AUTORES}

Daniel Fabian Bettú é Geólogo formado pela Universidade Federal do Paraná (UFPR-2002) e Mestre em Geologia Exploratória pelo Curso de Pós-Graduação em Geologia na mesma universidade (UFPR-2004). Atualmente trabalha como consultor em empresa de prestação de serviços em geologia e meio ambiente.

Francisco José Fonseca Ferreira é Geólogo (UFPE-1970), Especialista em Geofísica Aplicada (UFBA-1974), Mestre e Doutor em Ciências (USP-1982; USP-1991), com atuação profissional na CPRM (1972-1980) e no IPT (1980-1990). Desde 1992 é Professor Adjunto do Departamento de Geologia da UFPR, onde ministra disciplinas de geofísica aplicada nos Cursos de Graduação e Pós-Graduação. A partir de 1998 coordena o Laboratório de Pesquisas em Geofísica Aplicada - LPGA/UFPR, onde desenvolve pesquisas multidisciplinares aplicadas à cartografia geológica e pedológica, exploração mineral e de águas subterrâneas e ao meio ambiente.

Eduardo Salamuni é Geólogo, graduado pela Universidade Federal do Paraná (UFPR-1986), Mestre e Doutor em Geociências (Geologia Regional) pelo Instituto de Geociências e Ciências Exatas da Universidade Estadual Paulista "Júlio de Mesquita Filho" (Unesp-Rio Claro-1991; Unesp-Rio Claro-1998). É Professor Adjunto (licenciado) da Universidade Federal do Paraná desde 1993, onde ministra aulas nas disciplinas de Neotectônica, Morfotectônica, Mapeamento Geológico, Geologia Estrutural, Geotectônica e Relatório de Graduação. Atualmente é Diretor Presidente da Minerais do Paraná S.A.

Luiz Alberto Fernandes é Geólogo (USP-1977), Mestre (USP-1992) e Doutor (USP-1998) em Ciências, Programa de Geologia Sedimentar, aperfeiçoamento na Universitat de Barcelona (1995), com atuação profissional na CETESB-SP (1978-1980) e IPT-SP (1980-1998). Desde 1998 é Professor Adjunto do Departamento de Geologia da UFPR, onde ministra disciplinas de Estratigrafia, Petrologia Sedimentar e Mapeamento Geológico na Graduação e Pós-Graduação. A partir de 2000 é Coordenador do Laboratório de Estudos Sedimentológicos e Petrologia Sedimentar LabESed-UFPR, onde desenvolve pesquisas aplicadas à exploração de recursos naturais e petróleo, geotecnia e meio ambiente. 